\author{
University of Cambridge \\ Helen Mussell \\ Centre for Gender Studies \\ POLIS (Politics \& International Studies) \\ All enquiries to: \\ hjm47@cam.ac.uk \\ www.gender@cam.ac.uk/directory/hmussell
}

\title{
The Nature of Social Responsibility: Exploring Emancipatory Ends.
}

\begin{abstract}
Social responsibility (SR) initiatives within a corporate environment (CSR) continue to be met with deep scepticism. My concern is with exploring this scepticism, which I argue is due to there being more to the underlying objectives of SR than has previously been investigated. I begin by outlining and substantiating my project as a social ontological enquiry, one in which I unpack key concepts to reveal the nature of SR. These ontological findings then underpin my argument that SR is problematically grounded in liberalist thinking, and CSR is in fact just one manifestation of SR. I advance the thesis that SR has emancipatory ends, of meeting human needs and flourishing, and that it is best explicated using feminist care ethics. The argument is then focussed on both shoring up and advancing the emancipatory project of SR. The scepticism of interest is revealed to be the incongruity between care and business; that businesses are deemed as being incompatible with SR, at least in their present capacity. Any claims to the contrary by the business community are branded inauthentic and the aforementioned scepticism ensues. The paper concludes with a brief discussion concerning implications for CSR initiatives and future changes and developments are considered.
\end{abstract}

\section{INTRODUCTION}

At first glance, the term social responsibility appears to be a buzzword. A dismissed contemporary concept predominantly anchored in its corporate manifestation as corporate social responsibility (CSR). But I want to argue that there is more to this ethically underpinned ideology of how an organisation, community or individual should act or perform than has previously received attention. My project here is to demonstrate that CSR is but one adapted form of social responsibility (from now on separated and recognised as SR), and that the values and objectives encapsulated in the latter have clear emancipatory ends. I will argue that the objective of many so called socially responsible initiatives is one of increased generalised flourishing. Of contribution to community, one of identifying, meeting and alleviating needs.

It is my further claim that through exploring these emancipatory ends, the contention and scepticism with which CSR is met can be explained. Millions of people invest their time and financial resources in such initiatives, including philanthropic endeavours, community volunteering, etc., so why are so many of them met with such deep scepticism? Why the contention surrounding CSR? 


\section{STRUCTURE}

I offer a fresh analysis and tackle this sceptical subject matter in three stages. The first starts by explaining and substantiating my use of an ontological approach. Simply put, this is where the analysis investigates and challenges implicit presuppositions about the nature of social reality. The benefits of using social ontology as methodology are also highlighted. I then start to explore some of the central terminology and concepts in question - namely those of responsibility, the 'social', SR and finally CSR - and I start to unpack their implicit ontologies. The result is a teasing apart of a number of philosophical presuppositions in which terminology is rooted, and the origin of the sceptical conflict becomes apparent.

These first stages of the analysis reveal why the underlying emancipatory objectives of SR are best explicated using a framework informed by a feminist ethics of care, that the meeting of identified needs through SR both incorporates and extends beyond social justice. Through extension of the logic of this argument, the subsequent claim is made that CSR initiatives also have emancipatory ends and are underpinned by an ethic of care. To be socially responsible in a business environment is to put caring on the agenda. The cause of the sceptical dispute towards CSR is traced as being grounded in a claimed incongruity of business and care, as opposed to business and responsibility. Contention is specifically isolated as to whether business can care. Throughout this first stage of ontological analysis, SR is shown to repeatedly challenge liberalist ideals, including the atomistic social ontology on which liberalism is premised and in which the nature of the moral agent is cast as strongly individualistic. SR is instead shown to bring a relational ontology to the fore, emphasising a social reality of inter-dependence, one where the moral agent acknowledges and seeks to maintain existing relations.

The second stage of analysis is concerned with explicating how SR initiatives are emancipatory. The task of interest here is to explore and consider the meaning of emancipation. Liberalist ideals implicit within widely held concepts of emancipation, along with the atomistic social ontology on which they are premised, are again revealed. The goal is to test conceptual boundaries, to challenge assumptions about what can be emancipatory, what becoming or being emancipated involves, and where emancipation can occur.

The final section is an investigation into the emancipatory reach of SR in a corporate environment, as CSR. The case for pursuing CSR is outlined. The paper ends with a brief appeal as to how SR needs to be followed through in order for its full emancipatory effect to take hold.

\section{SITUATING METHODOLOGY - SOCIAL ONTOLOGY}

A central tenet advanced here is that ontological enquiry is best suited to investigate the scepticism of interest. Before proceeding with this method, the claim that ontology can do the work required clearly warrants some substantiation. What then does an ontological analysis involve and how would it help in this task? 
The kind of ontological analysis to be undertaken here is one of social ontology; social in the sense of being concerned with those categories and systems which are human interaction dependent. The analysis is ontological in the sense of being concerned with investigating the nature, origin and development of the subject matter. It is an analytical process and a mode of philosophical enquiry, but it offers more than simple conceptual analysis. It goes further by drawing together a taxonomy (as the study of concepts and classifications) with a concern for understanding how such categories come into being, how they emerge through the social structure in which they exist, and how they contingently affect those structures. It combines philosophical enquiry and social theory; there is concern for both philosophical rigour and social analysis.

As a methodology, social ontological analysis acts as a sort of stripping back of a term, concept or category etc. It presents the opportunity to reveal the presuppositions that feed into the focus of the social enquiry, to consider theories and concepts which underpin, adjoin with and generate the terms in question. It uses philosophical enquiry to examine the nature of the social subject matter of interest. In this way it resonates with Gillian Howie:

The work of philosophy should be concerned with the intelligibility of the world. This is not because everything can be explained, grasped, or even communicated, but because if, as feminists, we wish to change the world, then we need to know what we are dealing with. (Howie, 2010, p. 9 - emphasis added)

What then are the benefits of this approach? Firstly it is far-reaching in its capacity to excavate, contributing philosophical rigour to the use of terminology and seeking internal coherence. It offers the chance to trace the origin and subsequent development of categories, terms etc. and to locate them within their nexus.

But in the context of social ontology the philosophical rigour goes beyond conceptual analysis. With social ontology the insights of the analysis can then inform approach or strategy. In short, once we better understand what we are dealing with, we can formulate the best tactics for interacting with it i.e. through observation, identifying reasons for failure of a project, unexplained contention etc. As a result we can better situate what we are dealing with within social theory, thereby being in a position to offer further explanatory detail.

It follows then that what is also required is a conception of the social structure and processes within which the social category or term of interest exists - a developed conception of social ontology. Fortunately a number of social ontologies have been developed by leading social theorists as attempts to account for the nature of our complex social reality and how it comes to exist. Amongst such developed social ontological theories is the work of Tony Lawson (1997, 2003, 2015), whose conception of social ontology is drawn upon here.

Writing in a recent position paper (2015) in which he outlines the social ontology underpinning the work of a group of Cambridge researchers, Lawson lays out and differentiates two key aspects and lines of enquiry of social ontological analysis - social scientific and social philosophical ontology. Briefly summarised, the former of these is "The 
study of what is, or what exists, including the study of the nature of specific existents" (Lawson, 2015, p. 19). As such, we can see how the investigation being undertaken here constitutes a social scientific ontological analysis, i.e. an enquiry into the nature of social responsibility as a social existent. The latter, philosophical ontology, is quite simply "The study of how existents exist." (Lawson, 2015, p. 19 - emphasis added).

Up until recently, philosophical ontology has been the primary concern of the Cambridge project. The result of this focus is a social ontology of advanced theories of social structure, one acknowledging social reality as an open system in process. A social ontology emphasising relations, interaction and emergence. This highly relational social ontology is set in direct contrast to a more atomistic one, characterised by the belief in closed systems, of predictable and regular events, an ontology beset with isolationist tendencies. To illustrate how such an atomistic ontology is often presupposed, the use of mathematical modelling in economic theory provides a helpful example. The representation of social entities by numerical indicators in models relies on an isolationist approach, i.e. that they are separable and can be represented outside of a relational context. This is simply required for the maths to work. The maths cannot accommodate an entity changing, shifting, or being affected by relation to another entity mid-model. Maths requires fixity, isolation and permanence; this is simply required to get the maths going. And the use of these models for deductive reasoning purposes also presupposes that regular or predictable events will occur. In this way we can see the sort of atomistic social ontology presupposed by the use of mathematical modelling.

Social structure in the Cambridge project is also theorised through the role of rights and obligations, of social positioning, of rules and power. Social relations, including community and organisational structure also feature heavily. Social processes are theorised through emergence and transformational processes, with the result that "The conception arrived at is one of emergent social structural organisation in process." (Lawson, 2015, p. 41).

Recalling the differentiation between the social scientific and social philosophical projects is important. It highlights how a scientific ontological analysis of the kind being undertaken here is focussed on the development of the actual existent. Whilst it is important to explicitly acknowledge that this investigation locates the existent of SR within the philosophical social ontology of an emergent and relational social structure in process as outlined above (doing so in clear contrast to an atomistic one), the objective here is not to focus on SR in philosophical ontological terms i.e. to study how it exists, say for example as an emergent property or collective practice. Whilst the two ontological projects are contingent and complimentary, and it is important to acknowledge that "Philosophical ontological findings can be said to be helpful to the task before us [scientific ontology]" (Lawson, 2015, p. 43), the project here is concerned with investigating the development of the concept. To do so using a more explicit philosophical ontological analysis is undoubtedly an important and complimentary project requiring exploration elsewhere.

By choosing the social scientific ontological analysis approach outlined above I can investigate the nature of SR as a social existent. I can show how SR is underpinned by a 
relational ontology, as opposed to an atomistic one presupposed by liberalism. And importantly for the purposes of this paper, I can then use this analysis to explain why CSR initiatives are met with such scepticism. In this respect, the ontological analysis not only traces the development of the concept and the theoretical framework with which it engages. It also addresses why the social context (i.e. corporate) proves to be particularly problematic. What follows is an ontological analysis of SR and associated terms.

\section{AN ONTOLOGICAL ANALYSIS: STAGE I}

\section{Situating Responsibility}

How best to interpret the phenomenon of SR? It is important to start at the basics, by highlighting that SR is classified as an ethical issue. Questions concerning that for which we are and are not responsible (which are among the sort raised by SR) constitute the problems of normative ethics. It is within normative ethical theory that matters pertaining to what one should and should not do, along with the principles that govern these issues, are debated. There is not the room here to elaborate on the complexities of moral responsibility in all socio-cultural contexts, but for the purposes of this paper I am situating responsibility in the Western liberalist tradition. I do so because the concept of SR is grounded in liberalist thinking (as will become apparent), and this necessitates the use of a liberalist framework for explicatory purposes.

Western normative moral theory is grounded in the liberal moral tradition of rights of the individual. This tradition focuses predominantly on determining and protecting those rights and it uses a justice framework to do this. The normative theory draws heavily on a Kantian framework which locates the moral agent as individualistic, placing rights to autonomy and liberty at the centre of this justice perspective. This Kantian framework not only underpins the work of key justice theorists such as John Rawls and his Theory of Justice (1971), whose 'original position' demonstrates a "Metaphysical assumption of abstract individualism" (Jaggar, 1983, p. 30), but it also feeds directly into the legal framework which props up and maintains this justice perspective. The result is a contingent system of moral-political-legal theory that re-enforces itself. It is this individualistic justice perspective, the likes of which Rawls's theory represents, which I will go on to argue is insufficient for the task in hand.

The moral issues raised by questions pertaining to social matters, such as the extent of one's SR, tend to be viewed through the lens of this liberalist normative ethical framework. Emphasis is placed on determining the degree to which a moral agent's liberty and autonomy should be affected, with the starting point being the nature of the moral agent as an individualistic and independent self.

Viewed from this individualistic perspective, responsibility is a necessary partner of rights to ensure that relationships between individuals are established and maintained; that detachment and atomism are avoided. Responsibility as duty in this sense serves as societal glue - it is accepted that with rights come responsibilities. This liberalist view of responsibility has 
implications for why an individual would choose to be socially responsible, about their motivation for assuming a position of duty. Complicity with responsibility in this sense arises because of an implicit social contract, as a way of preserving and maintaining ones rights. But there is another view of responsibility that refocuses why an individual chooses to accept and comply with responsibility, one that starts from a relational ontology as opposed to an individualistic stance. Here the individual views responsibility as a way of maintaining existing relationships. This is the perspective from an ethic of care. Selma Sevenhuijsen offers a summary of the two positions:

While the moral subject in the discourse of individual rights looks at situations of moral dilemma from the stance of the 'highest principles' and takes rights and obligations as a means of establishing relationships, the moral subject in the discourse of care already lives in a network of relationships, in which s/he has to find balances between different forms of responsibility (for the self, for others and for the relationships between them). (Sevenhuijsen, 2000, p. 10)

The rationale for being responsible according to each discourse changes. For liberalism the end is a relationship for individualistic purposes and the means is taking on responsibility. For an ethic of care the end is maintaining relationships and the means is balancing responsibilities. We can see how these two approaches affect how an individual may regard and proceed with responsibility. The who or what the individual is looking to establish a relationship with or is in a pre-existing relationship with, will guide both the choice and nature of the responsibility assumed.

This leads us to consider why an individual might choose to be socially responsible, what that might involve, and what their motivational ends may be. The focus here has been to link responsibility with relationship. The result has also been one of exposing how a liberalist conception of responsibility depends upon an individualist or atomistic social ontology, viewing responsibility as a necessary partner to rights. The conception of responsibility from an ethic of care has differentially been shown to draw upon a relational ontology, seeking instead to maintain existing relationships. The next step is to determine with whom or what a relationship is either sought or maintained when being socially responsible. It is to determine the 'social'.

\section{Situating the Social}

Another feature of the liberalist justice approach is its heavy reliance on the distinction between the public (read political) and private (read non-political) domains as a central tenet to societal structure. It is this classification which determines the criteria for where the political state can and cannot intervene; the private domain being supposedly being off limits from state intervention in the name of the preservation of individual liberty and freedom from interference. 
Bearing this classificatory system in mind, determining that which falls into each liberalist domain reveals crucial clues about the nature of SR. It does so in terms of isolating what or where the social might be, but also in terms of understanding the sort of responsibility SR refers to i.e. voluntary, unregulated etc.

How best then to investigate the societal divisions which sit at the centre of liberalist theories of justice, and the premises on which these divisions rest? I start with Ruth Abbey:

The term 'private' is inherently ambiguous. As a contrast concept to 'public', the designation can refer to (i) civil society (voluntary organizations and associations that exist between the family and the state); (ii) the economy; and (iii) the household or domestic realm. These three spheres are very different from one another in terms of functions and dynamics. The 'private' seems to serve as a residual category, containing anything that does not, in principle, call for state regulation. (Of course in practice the state is involved in all of these areas). So instead of relying on a binary distinction between public and private, we need to distinguish the public from civil society, from the economy, and from the household, all the while acknowledging that none of these separations are neat, clean or complete. (Abbey, 2011, p. 12)

That such neat societal distinctions are even supposedly possible once again points towards the strong atomistic tendencies in the ontological thinking that underpins liberalism i.e., that society is clearly separable. But Abbey's observations go further than highlighting this liberalist presupposition. She also provides a helpful extended analysis of those aspects of society which are pooled into the 'residual category' of the private. As she notes, these are drawn together on the same premise; that they require no state regulation or intervention. They are to some degree all assumed to be 'apolitical', thus deserving of the privacy achieved from being located within the 'private' sphere.

This is interesting for two reasons. Firstly, it provides a richer picture of that which supposedly constitutes the non-political, the private, elaborating on the traditional dichotomy. Secondly, her summary reminds us of the workings of an outdated classificatory system which determines 'civil society' and 'the economy/business' as private. By stripping back the liberalist societal structure to a deeper level she exposes an original distinction which is not always brought to the fore; that both of these are supposedly non-political.

This is important. It exposes a central ambiguity regarding details of that which is included and excluded in the 'private' sphere, and on what basis. Abbey rightly appeals for consistency, clarity and a move away from distorting dichotomy. But what Abbey does not highlight is the contextual variance with which the public-private distinction differs, of the conditions under which the classification (often conveniently) changes. This propensity for shifting is an issue Susan Okin draws attention to. In clarifying her own position in terms of the public-private, she acknowledges Pateman and Olsen's work, noting that: 
[Carol] Pateman and Frances Olsen have both helped to expose a major ambiguity in the language of 'public' and 'private': sometimes it has been used to separate the state from the rest of society, including the market and the family, and sometimes to separate the state and the rest of nondomestic life from the family. Because here I address the second dichotomy, I use the terms public and domestic. (Okin, 1989, p. 198 ${ }^{\mathrm{i}}$ )

The limitations that result from the over-simplified and unsophisticated liberalist publicprivate dichotomy have been central to leading second wave feminist theorists such as Okin. Her focus is on 'the second dichotomy', of the separation of the domestic from the rest of society. My focus is different, yet some of the central concerns are still shared. Whilst Okin's interest addresses the problems caused by liberalism's 'second dichotomy', the focus here is on the problems and implications caused by the first; of the separation of the state from the rest of society. It is by exploring this distinction that we can start to elucidate 'the social' and ultimately how it sits in relation to the economy and business.

What has this got to do with SR and situating the social? The implications of classifying sections of society as private or public is not just a problem of mislabelling. It concerns the benefits and advantages afforded by these classifications. In liberalist theory the private as non-political is subject to the liberalist mechanism of non-interference, in the preservation of liberty. This flows from the premise that the private sphere has no political leverage and should subsequently be free from state interference and left to 'self-regulate'. Indeed, with regards to situating the economy as private, this liberalist self-regulatory mechanism is deeply embedded in early $\left(18^{\text {th }}\right.$ century) liberal economic theory. Adam Smith devised his 'invisible hand' (which forms the cornerstone of modern day anti-regulatory economic theory) to reside over and self-regulate a supposedly non-political economic sphere, one where business and government stayed out of each other's way.

So where does the social feature within this liberalist system? Let us recall Abbey's definition: "Civil society (voluntary organizations and associations that exist between the family and the state)." (Abbey, 2011, p. 12). This sphere is also referred to as the "third sector', the sphere in which voluntary, not-for-profit, NGO's and community work is situated. The third sector is also where increasing amounts of corporate philanthropic activities such as foundations are located ${ }^{\mathrm{ii}}$, activities which constitute CSR practice, and it is often said to be located at the intersection between the public (state) and the remainder of the private sphere. It is arguably this sphere which can be most strongly identified as the site of 'the social'. It is within this sector of society (designated as supposedly politically neutral by the liberalist tradition) that any failures of provision by either the public sector (as the state) or the private sector (as the family) are 'picked up' and accommodated for, where those deemed as being in need are cared for. 


\section{Situating Social Responsibility}

Identifying the third sector as the site of the social has a number of implications. We can start to develop an advanced understanding of for whom or for what it is that one is assuming responsibility when an individual chooses to volunteer to be socially responsible. We can begin to determine the nature of the relationship. The scientific ontological approach locates the sort of responsibility SR refers to and why. It is to voluntarily assume responsibility to care, to alleviate the needs of others, needs that are otherwise unmet by both the public sector and the family. To choose to be socially responsible is to respond to others (importantly unknown peoples' i.e. strangers) needs. It is to show concern, to care. It is to demonstrate sympathy and benevolence to those outside of one's immediate domestic circle (familial and friendship). It is to endeavour to emancipate individuals by serving their needs, to assist them in their flourishing. It is to choose (within a traditional liberalist structure) to go beyond one's apparent (sphere of) duty (to be supererogatory), to extend one's responsibilities, as opposed to seeking to limit one's responsibilities. It is to contribute to community and generalised flourishing. In social ontological terms, social responsibility is clearly shown to be highly relational.

Determining the nature of SR as voluntary due to its connection with civil society and the third sector is important. Crucially for liberalism, grounded in and presupposing an atomistic ontology, the rights of the individual continue to be conserved as long as the act of assuming $\mathrm{SR}$ is voluntary, as long as the responsibility of SR is optional. This is essential for preserving the distinction between the sphere of civil society and the remainder of society (which is somewhat reminiscent of Okin recognising strategic dichotomies). But contention exists, because for liberalism to even choose to volunteer to take on additional responsibilities is problematic. As Virginia Held notes: "The liberal model assumes indifference to the welfare of others [...] it promotes only calculated self-interest and moral indifference." (Held, 2006, p. 83).

It is apparent that there is further contention requiring explanation in light of having identified the sort of responsibility SR entails. The scientific ontological analysis makes clear that the drawing together of the social with responsibility reveals something particular about the kind of responsibility involved. We have seen that to volunteer to be socially responsible is to acknowledge that there are other's needs to be met. It is to be motivated by empathy, to demonstrate care and concern. It is to choose to extend ones immediate circle to meet these needs. It is to situate oneself among the social, the community to which responsibility is volunteered. In doing so, the individualist and self-interested moral agent at the centre of liberal theory is brought into question, as is the atomistic social ontology liberalism presupposes. Instead, the moral agent acknowledges (to differing degrees) their connection to others, their inter-related status as a social being. A more relational social ontology takes precedence. There is a palpable shift in perspective, which can be explained as follows:

From a justice perspective, the self as a moral agent stands as the figure against a ground of social relationships, judging the conflicting claims of self and others 
against a standard of equality or equal respect. From a care perspective, the relationship becomes the figure, defining self and others. Within the context of relationship, the self as a moral agent perceives and responds to the perception of need. The shift in moral perspective is manifest by a change in the moral question from 'What is just?' to 'How to respond'. (Gilligan, 1982, p. 23)

The liberalist justice perspective appears limited in understanding the nature of SR and the atomistic ontology on which liberalism is premised is called into question. Whilst liberalist justice offers an evaluative framework for weighing up and apportioning accountability for need, and can assess whether an individual's need is just (deserved), it cannot fully accommodate the action of responding to that need by taking responsibility to help fulfil it, when it was not in fact caused. This is why in liberalism civil society is located in the private non-political sphere, the sphere where justice is not 'required' to intervene.

Yet there is an increasing emphasis placed on the acknowledgement that SR is not simply a benevolent response. It is an acknowledgement of inter-dependency within a connected, emergent social system. The emphasis shifts to a recognition of existing relationships (i.e. an individual's relationship to their community, to their natural environment), as opposed to the establishment of new relationships. In this respect SR is not seen as a new endeavour but the recognition of a responsibility towards a pre-existing network of relationships which require maintenance, a position espoused by moral subjects with a caring perspective. A relational social ontology is brought to the fore, emphasising existing connections, not an atomistic one, which as we have seen emphasises establishing new relationships between separated individuals.

But there are voices of concern about the levels of responsibility being assumed by individuals in a wider political context, that the increasing emphasis on personal responsibility echoes a neo-liberalist agenda. Concern is focussed on the role of State minimisation through a process of farming out of responsibility, of a reduction of the public sphere through an expansion of the third sector. This is a position outlined by Grahame Thompson in which he identifies that:

There is indeed what might be called a coherent, large-scale 'responsibilisation' process underway, led by governments and public authorities and experienced in their daily lives by citizens and employees [...] Its distinguishing element is that it does not require citizens necessarily to comply with rules or regulations, nor to obey an authority. Rather it involves an un-coerced application of certain values rooted in the motivation for action. It seems to be fundamentally premised on the construction of a moral agency that accepts the consequences of its actions in a self-reflexive manner. (Thompson, 2007)

The claim that increasing personal responsibility is part of a neo-liberal agenda is an important issue; connections between SR and citizenship require investigation. I do not have the space here to develop the idea, but I would argue that increasing emphases on citizenship, 
via citizenship education and through the role of corporate citizenship as a central tenet of CSR, reveals it to be a vehicle through which SR is delivered. To reiterate, the civic sector, to which citizenship is directed, is the third sector, or the social as previously identified. Clearly further social ontological analysis is required into the nature of citizenship to draw out connections.

Returning to the concerns of this paper, I argue that explicating the nature of the moral agency identified by Thompson and the sort of values that underpin it are crucial to understanding SR, to understanding why some people choose to inhibit their (liberalist) personal freedoms by assuming (voluntary) responsibilities. As Thompson directly acknowledges, this 'responsibilisation' does not ring of duty, of adherence to law and principle. Instead it appeals to something else - to 'certain values rooted in the motivation for action'.

Determining this motivation for action and the moral agency of individuals in their capacity as consumers is picked up through another aspect of 'responsibilisation'; 'consumer social responsibility'. Similar to Thompson's suggestion that motivation is not duty bound, Lombardi and Tammelleo report similar findings from a study of consumer boycotts. They report that: "Efforts to generate consumer support eschewed claims associated with rulebased obligations in favour of appeals more typically associated with virtue and caring ethics." (Lombardi \& Tammelleo, 2014, p. 99). More explicitly than Thompson however, these findings turn directly to care ethics to locate the motivation behind moral agency. In doing so, the authors link back into Sevenhuijsen's observation of earlier, that "The moral subject in the discourse of care already lives in a network of relationships" (Sevenhuijsen, 2000, p. 10). In short, Lombardi \& Tammelleo's moral subjects are presupposing a relational social ontology.

The concept of SR appears to be confronting the justice-care debate head on. It is pushing the justice framework to its limits, showing that it cannot reconcile the sort of responsibility outlined above. SR appears to contest the atomistic liberal model that "Assumes indifference to the welfare of others" (Held, 2006, p. 83). The intellectual infrastructure that liberalist justice offers is old and slow. It is buckling under its outdated and implicitly biased premises. As Liedtka notes when justifying how a care-based ethic better addresses fairness:

Equality no longer corresponds with equal rights or equal treatment; rather it requires that we view each member as worthy of equal respect and consideration, and respond to the unique needs they bring with them. (Liedtka, 1996, p. 195)

By identifying the third sector as the site of the social, we can see how the political and the moral are drawn together in an expanding and contested domain. It challenges us to think if and how a justice and care framework can work together and tests previously accepted and restrictive liberalist boundaries. As Joan Tronto notes: 
While our current concepts could be extended to include concerns of care, the boundaries that circumscribe how moral concepts might be used in our current modes of thought foreclose such thinking. Theories and frameworks exert a power over how we think; if we ignore this power then we are likely to misunderstand why our arguments seem ineffectual. (Tronto, 1994, p. 4)

To this extent SR raises important issues concerning liberal social structure, the rights and responsibilities of the individual and of moral agency. And importantly, for this paper, SR appears to directly challenge the atomistic ontology central to liberalism, instead pointing towards a more relational ontology to explain SR choices.

\section{Situating Corporate Social Responsibility}

All of the above leads us to consider the activity of SR in a corporate context. What sort of SR is this? As with SR, are businesses demonstrating a caring perspective, trying to identify and fulfil needs? Are these the same needs as those in the third sector which SR seeks to address?

The question regarding who or what the corporation is socially responsible for is prevalent throughout CSR discourse. As Carroll notes: "The word 'social' in CSR has always been vague and lacking in specific direction" (Carroll, 1991, p. 43). The identification of the third sector as the site of the social can help tackle this. It can explain why there has been a long history of voluntary involvement by business in the third sector, an example of which is corporate philanthropy.

Regarding linking CSR to care, even a cursory glance through CSR literature in the form of company websites etc. reveals a connection. An aspirational caring agenda underpins CSR activities; companies espouse caring identities. Examples abound. Corporate community involvement (CCI) projects (where employees volunteer with charities of their own choice) are trademarked as caring ${ }^{\mathrm{iii}}$. Industry wide initiatives such as Responsible Care $\AA^{\mathrm{iv}} \mathrm{do}$ likewise. Sell-out business conferences for CEO's are entitled 'Who Cares Wins'v . Leadership programmes list 'a caring attitude' ${ }^{\text {vi }}$ among the top characteristics of successful business leaders. The objective to connect business and care is conspicuous.

To be 'socially responsible' in a business environment is to put caring on the agenda. We can see from the examples above that emphasis is placed more on care than on that of responsibility. Despite using the justice based liberalist moral language of responsibility (as in $\mathrm{CSR}$ ), businesses draw on care based discourse, shoring up the argument that SR breaches the boundaries between justice and care.

The caring perspective is evidently causing problems of the sceptical kind. This scepticism is grounded in claimed incongruity between business and care, or more specifically of whether business can care. This compatibility issue and potential of businesses to be ethical has long been debated. As Nelson notes: 
Perversely and ironically, the misconception that corporations cannot be ethical lets them off the hook for social responsibility, creating a permissive attitude for misbehaviour. If we are to survive and flourish, as a species as well as individuals, we have to act as a whole people, body and soul together. (Nelson, 2006, p. 8)

Of interest here is the sort of ethics involved; that contention is caused by CSR because it pertains and purports to care. But these complaints are directed at institutional capability, not at the activity itself. At the level of individual agency, CSR does identify and meet needs. Individuals do volunteer their time and become involved with CSR projects. Determining the emancipatory potential of these need fulfilling activities is my next task.

\section{AN ONTOLOGICAL ANALYSIS: STAGE II}

\section{Situating Emancipation}

The task here is to flesh out the terminology of emancipation. In doing so we will see how the concept of SR aligns with an emancipatory agenda, how voluntarily assuming a position of SR can in fact be emancipatory.

Determining what emancipation is, and has been taken to mean, is a difficult task due to ambiguity. This is a position commented on by Jan Nederveen Pieterse:

Flag words in political analysis and policy, such as participation, emancipation, empowerment, have rarely been clearly defined, or for that matter referred to in indexes, another indication of their un-reflected use. The cornerstones of analysis have often been the most casual elements. (Pieterse, 1992, p. 5)

Similar to Abbey's concerns regarding ambiguity of the term private, so Pieterse draws attention to the 'un-reflected use' of emancipation. Agreed definitions are opaque and conceptual development unchartered. The instability that a lack of reflection can lead to is hinted at, with the problematic level of internal incoherence only exacerbated by inconsistent use of terminology.

Pieterse charts how the meaning of emancipation has been subject to change over time. It has seen great variation depending on its 'application', to the sort of thing being emancipated or undergoing emancipation (i.e. personal emancipation, class emancipation, gender emancipation etc). This suggests that meaning is contingently linked to context. These findings are reminiscent of the analysis of SR; that the nature of responsibility changes through the social context (i.e. taking on a voluntary nature). Both sets of findings reveal the importance of explicitly situating a term contextually when it is used and in exploring a particular use of a term when it has not been made explicit. Generalized use should be avoided and contextual conceptual coherence encouraged. 
An important task here is to be clear about the sort of emancipation being referred to. To do so is central to demonstrating how emancipation is linked with and achieved through SR. It will be helpful to start by outlining previous conceptions of emancipation, to start at some basics by tracing the conceptual development during the Enlightenment period. Here we can see intriguing similarities to that of the concept of responsibility. Again, the political context is paramount, linking the use of emancipation with the project of Liberalism, or Liberal democracy. This link explains the development of the concept of emancipation as one concerning freedom, of a move towards a position where an individual's rights are both acknowledged and given the opportunity to be met. The underlying theme of the process of emancipation as underpinned by liberalism is then one of a struggle; of a (progressive) movement by an individual or group towards the opportunity and right to realise and maximize an acknowledged potential; to be free from externally imposed (social) constraints.

Liberal emancipation is then premised on an atomistic social ontology, placing the very possibility of the individual to be free of constraints at centre stage. What those constraints are defined as being, and what freedom is being sought, depends on the context. It is both a process and an end goal:

Emancipation tends to be used in two related ways: the process of the disadvantaged entering the mainstream, including women's liberation, and in a general sense of 'becoming free', the character of which varies according to the understanding of constraint. (Pieterse, 1992, p. 9)

Emancipation is linked to maximizing and fulfilling potential. This includes recognising and defining what potential exists and how to achieve it. In the context of SR this would be the potential to care, to maintain existing social relations. This all sounds positive and liberating, (which of course is the ultimate goal in a liberalist context), but one cannot immediately be emancipated following the recognition of constraints. A transitional process is required, in which the acquisition and achievement of necessary resources to bring about emancipation occurs. One in which constraining power structures are identified and the very position of being constrained is acknowledged. This pre-cursor process is empowerment, where a subordinated group transitions and mobilizes from a discredited and/or inferiorized status.

\section{Achieving Emancipation: The Crucial Reach Beyond Empowerment}

Empowerment also has its own limitations. It does not demand the dismantlement of recognised constraining power structures and it can leave the problem intact unless progressed to an emancipatory stage. As Pieterse puts it:

It [empowerment] does not necessarily problematize power [...] it is politically neutral. It does not necessarily imply a critical consciousness. Empowerment may relate to emancipation as a necessary but not a sufficient condition: emancipation implies empowerment, but not every form of empowerment is emancipatory. (Pieterse, 1992, p. 11) 
Empowerment and emancipation must occur (respectively) sequentially. The latter (which depends on the development of critical consciousness to problematize the constraining power from which emancipation is sought) cannot be achieved without the former (through which necessary means and resource are accumulated with which to become emancipated). The problem within the sequence is that the process started by the former may stall before the project progresses to the latter.

Why be concerned with this in defending the thesis that SR has emancipatory potential? For an answer I return to the earlier comment of Thompson and the process of 'responsibilisation', which he considers dubiously linked to neo-liberalism. His concerns are separated into two camps: i) the responsibilisation of the individual and ii) the responsibilisation of autonomous agents (companies) in the social-economic sphere.

The first relates to the onus placed (by external influences) on the individual to be responsible; to accept the consequences of their actions, to be self-reflexive. This sounds a lot like the responsibility identified as SR. It sounds like an empowering gesture, where one assumes responsibility for oneself. But this is Thompson's concern - it sounds empowering but this is not in fact the case. Individuals are instead asked to be self-governing and assume responsibility as part of a larger scheme, to both i) reduce State responsibility and ii) to place emphasis on the individuals responsibility as a driver of markets. An example of the former is the drive towards the Big Society in UK politics, which sees a deliberate political strategy to increase the third sector whilst reducing the public sector. An example of the latter is advanced by free marketer CSR sceptics (advocates of deregulation), such as Elaine Sternberg who argues that SR should only be understood in individual terms, or as 'Conscientious Stakeholding' [sic]:

Properly understood, 'social responsibility' does not refer to any organisational responsibility to stakeholders. It instead designates a responsibility by stakeholders, to act so that their values concerning society are reflected in their actions. Social responsibility is exercised when individuals express their own values in their own acts, acting separately or in concert [...] What they choose has important consequences for business conduct, because the definitive business end makes it essential for businesses to heed stakeholder preferences. When each potential stakeholder-otherwise known as every member of society-acts conscientiously in his personal capacity, and strategically bestows or withholds his economic and other support on the basis of his moral values, free market forces will automatically lead businesses to reflect those values [...] Achieving social goals by way of conscientious stakeholding may be slow, and the outcomes may sometimes be disappointing, but voluntary action is a necessary condition of ethical conduct. (Sternberg, 2009, p. 9)

Sternberg fails to address a number of points here. Firstly, the effects that market forces have on individual's values, choices and consequent acts. She chooses to overlook how markets manipulate and control (through advertising, wages, etc.) the supposedly free choices and 
behaviour of individuals. Secondly, she avoids referring to how markets often strategically control access to information which 'conscientious stakeholders' require in order for fully informed moral reasoning i.e. conscientious or caring decisions, to occur. She omits to acknowledge that markets have become the arm which guides the invisible hand.

One wonders what Sternberg's enthusiasm for conscientious stakeholding (as opposed to CSR practices) would make of exposé NGO campaigns, such as those investigated by Lombardi and Tammelleo, which identify consumer social responsibility as being generated through appeals to an ethic of care. If her argument follows, then she should support such NGO projects, viewing the publicising of any information which may be required to make socially responsible/conscientious decisions as crucial for successful 'conscientious stakeholding'. But such NGO activity rarely involves just consumer awareness campaigns. Just like the markets they seek to hold to account, they employ tactics such as the lobbying of governments for increased regulation, the very activity which Sternberg objects to. Sternberg cannot have it both ways. Her argument fails to openly acknowledge the un-level playing field and power differentials between individual SR and the aggregate power of organisational SR (CSR). Considering the unequal onus she places on the responsibility of the individual stakeholder to steer the market, she needs to be more critical about the nature and extent of information made available which allows for the moral reasoning behind these empowering care driven conscientious decisions to be made.

Returning to Thompson's concerns regarding the outcome of the responsibilisation of autonomous agents (or more specifically businesses), the result appears to be different than for that of the individual. Here the strategy of increasing voluntary responsibility (via CSR) is rewarded in limited regulation. In this respect the issues raised by self-governance are far more problematic than that for the individual - they lead to a reduction of corporate governance by the State. The more a business assumes voluntary responsibility (in whatever guise that may be), the stronger it builds its case for less regulation i.e. it demonstrates its success of self-regulation.

The pattern we can see here through Thompson's outlined process of responsibilisation is the reinforcement of the liberalist structure of society as described earlier when situating the social. We can discern a distinct separation of the public sphere from the private spheres, which we must recall was originally founded on the belief that the former does not interfere with the latter on grounds of neutral political status, and due to the capability of the latter to apparently self-regulate. The expansion of the third sector through this process of responsibilisation is then a process of de-politicisation and privatisation, grounded in the false assumption that the private spheres hold no political leverage and are proficient at selfgovernance.

\section{Pushing the SR Project: Achieving Emancipation}

There is an aspect of this responsibilisation process that is being overlooked, an aspect which holds emancipatory potential. As Thompson notes, to choose to be or become responsible 
involves self-reflexivity, where the consequences of actions are considered and reflected upon. This is certainly the case for individual SR, which meets the conditions of critical consciousness and self-reflexive moral agency outlined by Pieterse as leading towards emancipation. Surely if fully progressed, this critical consciousness can lead to the problematization and dismantling of recognised power structures? If so, that would advance the process of assuming voluntary responsibility beyond that of empowerment. It would position the process of responsibilisation as being part of progressive empowerment. It would show it to have the potential to lead towards possible emancipation, if the project was successfully progressed and not abandoned at the point of empowerment.

Read in this light SR is empowering, it offers a route to emancipation. It lays the groundwork by exposing and recognising constraints and power structures which give rise to it as a response - even if it does not necessarily deconstruct them. That is the role of the next step, the emancipatory stage, which holds the potential. One can never just be socially responsible. One has to have reflected on why one should and wishes to be so in the first place, on why volunteering for such responsibility is necessary at all.

An emancipatory project lays out a path for the maximization of potential. By recognising certain constraints it can work around them (whilst not dismantling them) and present alternative futures. But an emancipatory movement may not be immediately recognisable, nor have its objectives set out clearly from the outset. It may be subject to ongoing change as specific causes become more apparent and take precedence. Identifying an emancipatory project in its infancy is problematic. What we need to look for are features which are identified as having potential, such as the movement of marginal groups to the mainstream, or of projects which encourage and foster co-operation of marginalised standpoints in a unifying fashion. Whilst the obvious programme of emancipation may not be in view, latent potential may be identified.

SR fits the emancipatory profile under certain (progressed) conditions. The responsibilisation issue of SR, problematized by Thompson as part of a neo-liberal agenda, is only problematic if it stalls in the empowerment phase. The identified emancipatory potential of SR can only be realised if the identified powerful constraints that have led to its inception and conceptual development are problematized and confronted. What it is important not to lose sight of is that the outcomes of socially responsible activities are ideally emancipatory in nature. Their ethical underpinnings seek to bring about flourishing, to create an opportunity to care, to alleviate need, and to emancipate individuals from suffering. In doing so SR also challenges the liberalist model, both in terms of its' atomistic social ontology and its' presuppositions regarding the nature of the moral agent, replacing these instead with a relational social ontology emphasising the inter-dependency of social reality. 


\section{CSR: WORKING THE CONCEPT, PUSHING THE AGENDA, ENFORCING EMANCIPATION}

A social ontological analysis has been undertaken in this paper to tease out conceptual connections and situate SR ethically and politically. The conceptual (in)coherence of emancipation has been addressed in order to explore SR as having emancipatory ends. A clear link between care ethics and SR has been identified. Theories of liberalist justice driven moral agency which presuppose an atomistic social ontology have been shown to be inadequate in their capacity to explicate SR. Care ethics has been shown to do the work of explaining the moral agency of SR more satisfactorily ${ }^{\mathrm{vii}}$, along with the relational social ontology upon which care ethics is premised.

I want to conclude the paper by arguing for the pursuit of SR in a corporate context. The point is that to withdraw support for CSR is to close the door on the emancipatory potential it has been shown to hold. A strategy of non-engagement inadvertently reinforces constraining power. As Nelson observes, it lets business off the hook and results in business as normal. Considering the aggregate power of corporations against the individual's power in terms of SR and change, this is a non-engagement strategy that can be ill-afforded.

There is resistance to pursuing CSR. The claim that CSR is part of neo-liberalist agenda to reduce the State is one example, and behind that sits the question of motive and authenticity. Both of these are valid concerns. The latter of these regarding issues of motive and inauthenticity stretches right back to the inception of CSR. Even Howard Bowen, who wrote the Social responsibilities of the businessman (1953/2013) in which the term CSR was first employed, openly acknowledged his own scepticism towards CSR being authentically pursued on a voluntarily basis. Discussing the ideas he presented in his 1953 text at a later date, Bowen made explicit reference to this scepticism and advised caution regarding CSR, noting that:

I was then skeptical and cautious but hopeful about voluntary social responsibility. My experience and observation since then have led me to the conclusion that the social responsibility concept is of minimal effectiveness and that an economy that serves the people can be built in America only if corporate enterprise is brought under social control on terms such that the public and not the corporations control the controllers. (Bowen, 1978, p. 129 - emphasis in bold added) $)^{\text {viii }}$

Similar concerns regarding control and authenticity are also raised by Theo Nichols in Ownership, Control \& Ideology (1969), where the relationship between ownership, control and the rise of managerial ideology in the advent of large scale corporations with remote shareholders is discussed. Investigating SR as business ideology, Nichols highlights a useful connection between ideology and conflict, opening up the question "If ideology is to be considered as a 'defence' this begs the question - 'then what is the attack?" (Nichols, 1969, p. 215). The reason this is of interest here, particularly in light of the recent critiques levelled at 
CSR as being a reaction to anti-corporate protest, is Nichols suggestion that not all companies interpret or use CSR ideology in the same way. It is open to broad interpretation, thus dependent upon the management's interpretation. To highlight this point and drive home the latitude of ideological interpretation, Nichols notes:

In short then - and we fell bound to stress this in view of some assumptions built into popular discussion of business social responsibility - these businessmen did not think of themselves as powerful figures who were in a position to redress some moral, social, or economic imbalance, of which, in any case, they gave no real sign that they were aware. (Nichols, 1969, p. 226)

In this respect, companies will pursue CSR on different grounds. Some will do so proactively and some reactively. Evaluating the authenticity of CSR ideology and practice is then steeped in problems.

To repeat, these concerns are valid, but the claim being made here that CSR should be pursued in no way refutes them. There is no contradiction here. In fact constant and consistent critical investigations of CSR in practice are encouraged. One of the identified stages of empowerment is the recognition of constraining powers; the suggestion is not to naively push ahead without strong critique.

That CSR is met with vehement scepticism and deemed a misfit reveals much about the constraining powers and limited scope of the current corporate context. The reaction towards CSR by free marketeers demonstrates this: "Businesses that even appear to accept conventional CSR, render themselves liable to be judged by its standards" (Sternberg, 2009, p.8). Avowals of shareholder primacy as the integral model of business, with activity or costs that deviate from the pursuit of profit seen as problematic, point towards the constraining nature of the economic rationality such avowals use. CSR clearly rubs up against this causing conflict. This is due to SR's ethic of care underpinning. CSR not only offers empowerment through recognition of constraints. It also problematizes this power and works to bring about change from within.

Instigating change from within is crucial. The messy threat that CSR (with its contrary moral agency of care ethics) presents to the supposedly unchallengeable ideology of the shareholder primacy model rooted in economic theory, is precisely why the pursuit of CSR holds so much emancipatory potential. It destabilizes. It is confrontational. It detracts and presents alternative possibilities. It does all of this right at the very centre of corporate power, demanding attention in the Boardroom. That there is concern amongst free marketeers that CSR is appeasement (or worse an admission of culpability) reveals the strength of the threat that it poses to the status quo.

Whilst concerns regarding the motives of CSR are valid, these do not warrant the outright refutation of CSR. Refutation would result in withdrawal from the Boardroom and risk 
closing down the dialogue between business and society. As Liedtka notes, an opportunity is seemingly presenting itself:

Ironically after decades of work by ethicists striving to humanize the work of market mechanisms, the market itself may be offering us an opportunity to use it to drive organizations to care. (Liedtka, 1996, p. 180)

CSR as the result of market demand is well documented and critiqued (the motivation concern). But by connecting SR to care ethics we can start to see why CSR is so incongruous. The care connection highlights the deficiencies and limitations of the current economic structures in which business operates. It exposes the shortcomings of the idealised selfinterested rational moral agent supposedly required for economic success, which sits at the centre of economic theory.

The choice of caring discourse as an aspirational ethical objective of commerce is a nod in the direction of acknowledging caring's universal appeal and ethical value. The argument here is not that the caring rhetoric be accepted as authentic without critique, but instead that these claims be used as leverage, as a standard against which CSR is measured. In short, CSR, if held to its caring account, could in fact be used to bring corporate enterprise under social control, benefiting both business and society.

CSR should not be seen as a result, a solution, but as a reparative response. The emancipatory potential of SR should not be abandoned within a corporate environment but should be pursued for its leverage. CSR should not stall at the point of apparent empowerment but should instead build on successes to date and bury down deeper into business, whilst maintaining strong visibility. Work is taking place beneath the surface to confront the incompatibilities and contentions which CSR exposes. As Eric Orts suggests: "What we need is re-conception of what the purpose of business is" "ix and I would add, "in order for business to be able to become socially responsible'.

\section{REFERENCES}

Abbey, Ruth. (2011). The return of feminist liberalism. Durham: Acumen.

Acquier, Aurélien, Gond, Jean-Pascal \& Pasquero, Jean. (2011). Rediscovering Howard R. Bowen's Legacy: The Unachieved Agenda and Continuing Relevance of Social Responsibilities of the Businessman. Business \& Society, 50(4), 607-646.

Bowen, Howard R. (2013). Social responsibilities of the businessman. Iowa: University of Iowa Press.

Buchholz, Rogene A. \& Rosenthal, Sandra B. (1999). Social responsibility and business ethics. In Robert E. Frederick (Ed.) A companion to business ethics. Malden (MA) \& Oxford: Blackwell. 
Carroll, Archie B. (1991). The pyramid of corporate social responsibility: Toward the moral management of organizational stakeholders. Business Horizons, July-August, 1991.

Gilligan, Carol. (1982). In a different voice: Psychological theory and women's development. Cambridge (MA): Harvard University Press.

Held, Virginia. (2006). The ethics of care: Personal, political, and global. Oxford and New York: Oxford University Press.

Howie, Gillian. (2010). Between feminism and materialism: a question of method. New York: Palgrave Macmillan.

Jaggar, Alison M. (1983). Feminist politics and human nature. Brighton: Harvester.

Lawson, Tony. (1997). Economics and reality: Economics as social theory. London and New York: Routledge.

Lawson, Tony. (2003). Reorienting economics. London \& New York: Routledge.

Lawson, Tony. (2015). A conception of social ontology. In Stephen Pratten (Ed.) Social ontology and modern economics. London \& New York: Routledge.

Liedtka, Jeanne. M. (1996). Feminist morality and competitive reality: A role for an ethic of care? Business Ethics Quarterly, 6(2), 179-200.

Lombardi, Louis G \& Tammelleo, Steve. (2014). Consumer social responsibility? Business and Professional Ethics Journal, 33(1), 99-126.

Nelson, Julie. (2006). Economics for humans. Chicago \& London: University of Chicago Press.

Nichols, Theo. (1969). Ownership, control \& ideology. London: George Allen \& Unwin Ltd.

Okin, Susan Moller. (1989). Justice, gender and the family. USA: Basic Books.

Pieterse, Jan Nederveen. (1992). Emancipations, modern and postmodern. Development and Change, 23(3), 5-41.

Rawls, John. (1971). A theory of justice. Cambridge (MA): Harvard University Press.

Sevenhuijsen, Selma. (2000). Caring in the third way: the relation between obligation, responsibility and care in Third Way discourse. Critical Social Policy, 20(5), 5-37. 
Sternberg, Elaine. (2009). Corporate social responsibility and corporate governance.

Economic Affairs, 29(4), 5-10.

Thompson, Grahame. (2007). Responsibility and neo-liberalism. Available at: https://www.opendemocracy.net/article/responsibility_and_neo_liberalism Retrieved $16^{\text {th }}$ November 2013.

Tronto, Joan C. (1994). Moral boundaries: A political argument for an ethic of care. New York and London: Routledge.

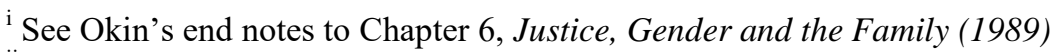

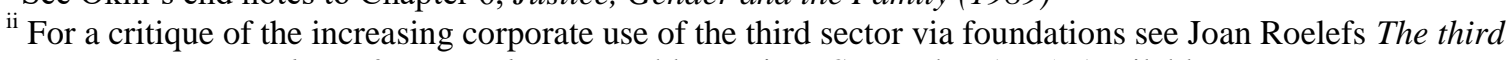
sector as protective layer for capitalism. Monthly Review, September 1995. Available at: (http://www.namebase.org/roelofs.html) Retrieved 14 ${ }^{\text {th }}$ December 2015.

iii See Cớres. (www.kohlscorporation.com/CommunityRelations/Community01.htm) Retrieved $13^{\text {th }}$ April 2013.

${ }^{\text {iv }}$ ICCA initiative: (www.icca-chem.org/en/Home/Responsible-care/) Retrieved $13^{\text {th }}$ April 2013.

${ }^{v}$ Conference details: (www.whocareswins.dk/en/Program.aspx) Retrieved $13^{\text {th }}$ April 2013.

${ }^{v i}$ Jane Nelson, Director of Harvard Kennedy School's CSR Initiative (www.hks.harvard.edu/mrcbg/CSRI/CPSL_the_edge_Jane_Nelson.pdf)

vii Other attempts to ground SR in philosophical frameworks do exist. Whilst the approach here is of a direct normative intervention with care ethics, the work of Buchholz \& Rosenthal also deserves a mention for their approach to underpin SR using American Pragmatism, see in particular Buchholz \& Rosenthal (2007) and their observation that: "There has been, and continues to be, a wealth of interesting and creative efforts to develop the normative dimension of social responsibility, which was beginning to drop out of consideration with the focus on corporate social responsiveness and public policy, and make it a central concern in dealing with social issues by, in some sense, redefining them as ethical issues and analysing them with normative frameworks" (Buchholz \& Rosenthal, 1999, p. 320)

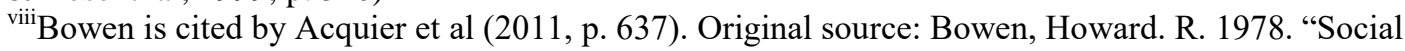
Responsibility of the Businessman - Twenty years later" in Rationality, legitimacy, responsibility - The search for new directions in business and society (pp. 116-130), Santa Monica (CA), Goodyear.

${ }^{\mathrm{ix}}$ Eric Orts, Professor of Legal Studies \& Business Ethics, Wharton (U-Penn), cited in From fringe to mainstream: Companies integrate CSR initiatives into everyday business, May 23, 2012 (un-authored) (http://knowledge.wharton.upenn.edu/article/from-fringe-to-mainstream-companies-integrate-csr-initiativesinto-everyday-business/) Retrieved $12^{\text {th }}$ December 2013.
} 